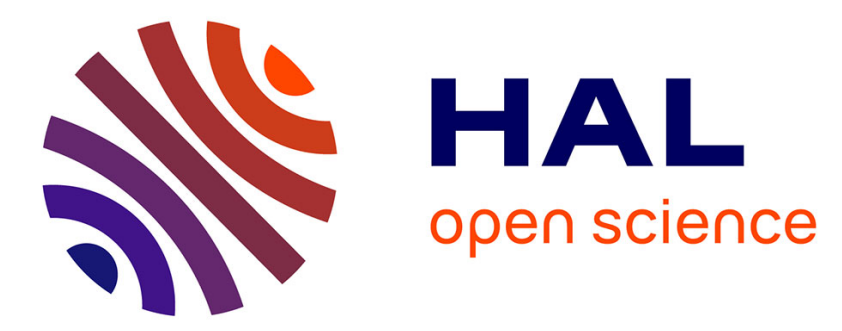

\title{
Local and global hydrological contributions to gravity variations observed in Strasbourg
}

Laurent Longuevergne, J. P. Boy, Nicolas Florsch, Daniel Viville, Gilbert

Ferhat, Patrice Ulrich, Bernard Luck, Jacques Hinderer

\section{To cite this version:}

Laurent Longuevergne, J. P. Boy, Nicolas Florsch, Daniel Viville, Gilbert Ferhat, et al.. Local and global hydrological contributions to gravity variations observed in Strasbourg. Journal of Geodynamics, 2009, 48, pp.189-194. 10.1016/J.JOG.2009.09.008 . hal-00707984

\section{HAL Id: hal-00707984 \\ https://hal.science/hal-00707984}

Submitted on 14 Jun 2012

HAL is a multi-disciplinary open access archive for the deposit and dissemination of scientific research documents, whether they are published or not. The documents may come from teaching and research institutions in France or abroad, or from public or private research centers.
L'archive ouverte pluridisciplinaire HAL, est destinée au dépôt et à la diffusion de documents scientifiques de niveau recherche, publiés ou non, émanant des établissements d'enseignement et de recherche français ou étrangers, des laboratoires publics ou privés. 


\section{Local and global hydrological contributions to gravity variations observed in Strasbourg}

5

Laurent Longuevergne (1)

Corresponding author laurent.longuevergne@beg.utexas.edu

J.P. Boy $(2,3)$

10 Nicolas Florsch $(4,5,6)$

Daniel Viville (7)

Gilbert Ferhat (2)

Patrice Ulrich (2)

Bernard Luck (2)

15 Jacques Hinderer (2)

(1) Bureau of Economic Geology and Department of Geological Sciences, Jackson School of Geosciences, The University of Texas at Austin, PO Box X, Austin, TX 78713, USA.

(2) EOST/IPGS (UMR 7516 CNRS-ULP), 5 rue René Descartes, 67084 Strasbourg, France

(3) NASA GSFC, Planetary Geodynamics Laboratory, Code 698, Greenbelt, MD 20771, USA.

25 (4) Sisyphe (UMR 7619 CNRS-UPMC), Université Pierre et Marie Curie Paris VI, Boîte 123, 4 place Jussieu, 75252 PARIS Cedex 05, France

(5) UMMISCO/IRD 32, avenue Henri Varagnat 93143 Bondy Cedex, France

(6) Dept of Mathematics and Applied Mathematics, UCT, South Africa.

(7) ULP-CNRS, Centre d'Etudes et de Recherches Eco-Géographiques (CEREG), UMR 7007, 3 rue de l'Argonne, 67083 Strasbourg, France

Keywords: superconducting gravimeter, local hydrology, global hydrology, soil moisture, water storage, Newtonian attraction 
We investigate the contribution of local and global hydrology to the superconducting gravimeter installed in the Strasbourg observatory. A deterministic approach is presented

45 to account for the contribution of the soils in the vicinity of the gravimeter: both amount and distribution of water masses are determined before calculating Newtonian attraction. No calibration is performed on geodetic time series.

Two multi-depth frequency-domain reflectometer (FDR) probes have been installed to 50 monitor the amount of water stored in the soil layer above the gravimeter. Since August 2005 , they have been monitoring the variation of the water content of the entire soil thickness. Several investigations have been undertaken in order to estimate the distribution of water masses: a precise local DEM has been established using differential GPS. The geometry and heterogeneity of the soil layer have been evaluated thanks to geophysical and geomechanical prospections. The comparison between observed and modelled gravity variations shows that daily up to seasonal variations are in good agreement. For long term variations, deep water storage and other processes have to be modelled to explain recorded gravity variations.

Abstract.1.1.

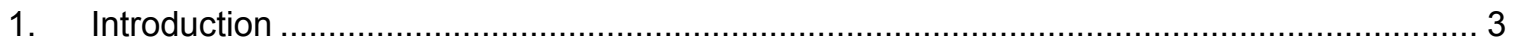

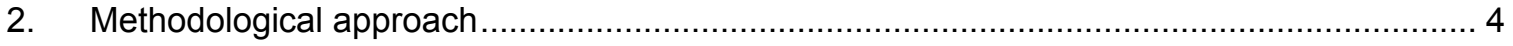

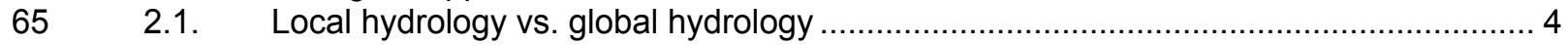

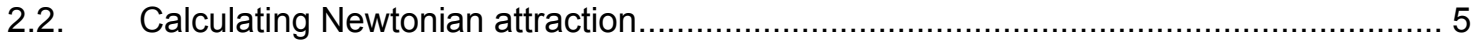

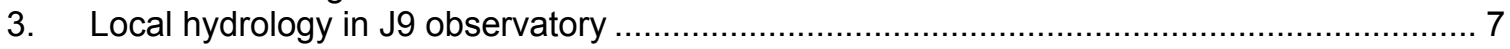

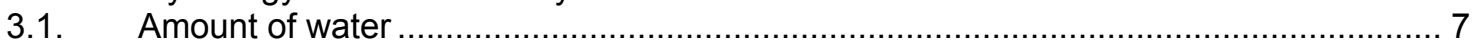

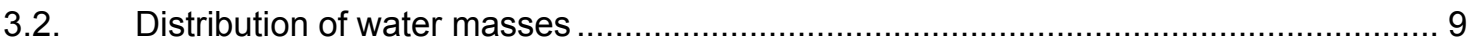

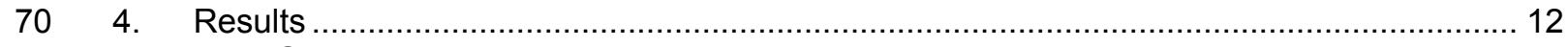

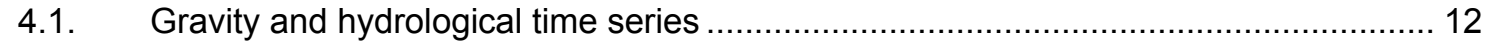

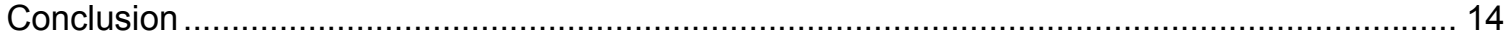

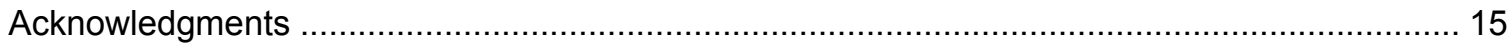

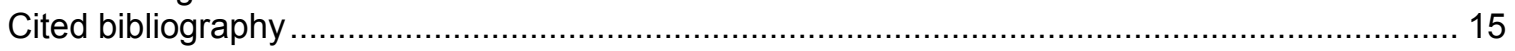




\section{Introduction}

80 Once the Earth tide is removed, hydrology accounts for a major part of the signal recorded by gravimeters and might hide delicate internal dynamical phenomena. Dal Moro and Zadro (1998) concluded that hydrological effects should be removed before studying signals of geodynamical interest. Moreover, in the quest to validate satellitederived gravity observations with ground observations, one should take into account the

85 difference between ground instrument-scale hydrological contribution and satellite-scale contribution (e.g. Hinderer et al., this issue).

Two methodologies have arisen to investigate hydrological effects. While both of them provide relatively good results, they are very different in terms of modelled processes and investigated spatial extent. The first methodology focused on local effects driven by Newtonian attraction. It is generally based on correlations studies between local hydrological measurements or models with gravity time series (e.g. Bower and Courtier, 1998; Crossley et al., 1998; Van Camp et al. 2006). Kroner and Jahr (2004, 2006) wanted to better understand the water fluxes around the gravimeter and so focused on isolated 95 hydrological processes thanks to controlled man-made hydrological experiments. Recently, some authors switched to a deterministic approach to evaluate Newtonian attraction (i.e. without calibrating on gravity data), leading to promising results (Hasan et al., 2005, Meurers et al., 2007).

100 The second methodology, a somewhat different deterministic approach considers the physical modelling of the hydrological contribution (Boy and Hinderer, 2006). Both surface loading and Newtonian attraction effects are calculated using global hydrological models (e.g. GLDAS (Rodell et al., 2004)). No calibration is performed on gravity data, so this process-oriented approach is likely to be more robust. However, this methodology 105 is limited by the spatial sampling of global models (at best $0.25^{\circ}$ ) as well as their temporal resolution (3 hours). Note that Virtanen et al. (2006) have set up hydrological models of several spatial extents in order to improve this approach. 
110 This work follows Boy and Hinderer (2006). We have set up a local hydrological monitoring system to better estimate water redistribution in the unsaturated zone at the scale of several hundred of meters around the gravimeter. Two main questions need to be answered before calculating the Newtonian attraction effect: what is the amount of water and where are these water masses? The first question will be tackled using soil moisture measurements. For the second question, we have positioned the gravimeter mass test inside its environment.

\section{Methodological approach}

\subsection{Local hydrology vs. global hydrology}

Two deformation processes forced by local and remote hydrological surface loads generate a measurable gravity effect (see Llubes et al., 2004): Newtonian attraction and surface loading, i.e. the elastic deformation of the earth crust due to the weight of water.

125 Traditionally, the hydrological problem has been separated into a 'local' and a 'global' contribution. This separation is more pragmatic than physical since Newtonian attraction has to be modelled for both local and global water distributions.

Figure 1 shows monthly gravity residuals (after correction of tides, polar motion and 130 atmospheric contribution) for 6 stations of the GGP network, classified with respect to the relative position of the gravimeter with the local soil layer. In one case, storing water in the local soil layer increases gravity; in the other case, gravity decreases. For stations above ground, the residuals show a clear annual signal with large amplitude (200 nm.s $\left.{ }^{-2}\right)$. Conversely, gravity residuals of stations below ground are two times lower and no clear annual variations may be extracted from the time series. This means that local hydrology and global hydrology create constructive and destructive interferences. As a consequence, both local and global hydrological effects are correlated and have the same order of magnitude, and both have to be modelled. 
140 The real difficulty of the hydrological contribution to gravity observations can be stated as follows: all local and global hydrological contributions are driven by climate and thus have a correlated behaviour at seasonal time scales. These contributions mix in gravity data so a robust estimation of the hydrological contribution should not calibrate local hydrological computations on gravity data. This has to be done on complementary information.

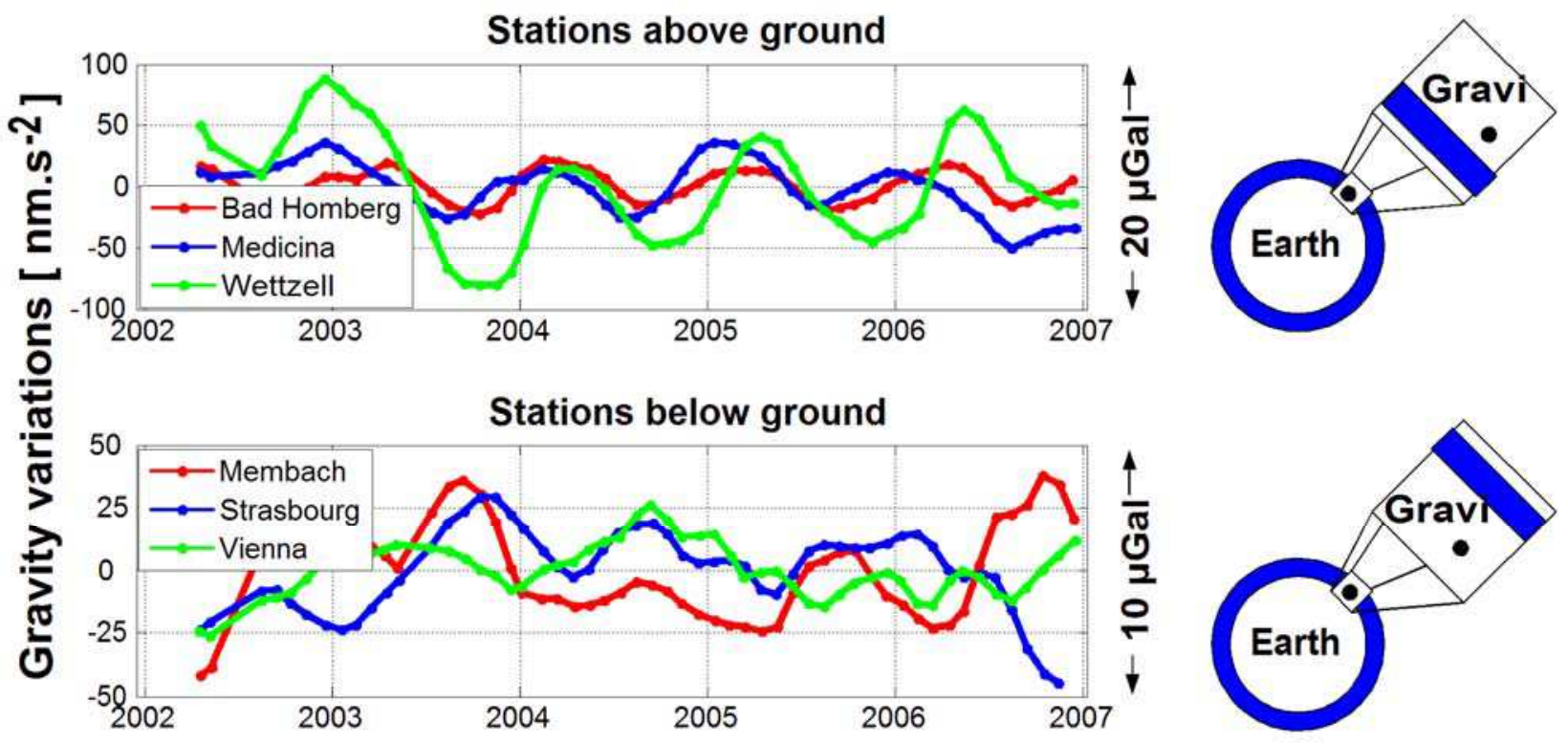

Figure 1: monthly gravity residuals observed at several GGP stations after correction of tides, polar motion and atmospheric contribution. Stations are classified with respect to the relative position of the gravimeter with the local soil layer, above ground or below ground. Adapted from Crossley et al. (2006).

\subsection{Calculating Newtonian attraction}

One question remains: where is the spatial limit between local and global hydrology? This question is important to precisely calculate the Newtonian attraction contribution but also to set up an adequate local hydrological monitoring system. In practical terms, when 
calculating the Newtonian attraction, all water masses should be taken into account but 160 they should not be included in both local and global zones.

The mechanical part of our problem was studied by Farrell (1977) among others. The gravity effect due to surface loads can be written as an infinite sum of Legendre polynomials. The effect of a unit point mass (or Green function) for a SNREI earth may 165 also be determined by calculating this infinite sum in the sense of distribution. The Green function of Newtonian attraction $G N$ for an instrument above the surface can be written as follows:

$$
G N(\psi)= \begin{cases}\frac{G}{4 a^{2} \sin (\psi / 2)} & \text { if } \psi>0 \\ 2 \pi G & \text { if } \psi=0\end{cases}
$$

where $G$ is the universal constant of Gravitation, $a$ the mean radius of the Earth, $\psi$ the 170 angular distance between the observation point and the point mass (see Boy et al. 1998). This way of writing the Newtonian attraction effect reflects that the Bouguer plate is $4 \pi G$ for a sphere and $2 \pi G$ for a flat infinite layer of unit density.

Local hydrology is described here as a Dirac function, but this expression is valid for a 175 spherical earth only. On the real Earth, topography quickly breaks spherical symmetry when getting closer to the instrument and becomes the major contributor of Newtonian attraction. The calculation of Newtonian attraction created by a uniform layer distributed on topography should be sufficient to determine the limit between local and global hydrology. This limit can be as far as several kilometres as shown by Meurers et al. 180 (2007). 


\section{Local hydrology in $\mathbf{J 9}$ observatory}

185

190

\subsection{Amount of water}

We have installed two Sentek Environsmart probes to monitor volumetric soil moisture 210 variations $\theta$ (see http://www.sentek.com.au). They are based on FDR (Frequency Domain Reflectometer) principle, i.e. the relative permittivity $\varepsilon_{r}$ of a soil volume (a capacitance) is measured determining the resonance frequency of an oscillator. These 
probes have multiple sensors installed along a vertical profile; they therefore allow the monitoring of soil moisture changes in the entire soil thickness. These probes have been 215 chosen because they are set up in a borehole access-tube, which has several advantages: (1) it minimizes soil and root disturbance so that the natural water flow is kept unchanged and (2) it makes maintenance easier, sensors are easily replaced. We have installed a 90$\mathrm{cm}$ probe in the $1 \mathrm{-m}$ thick loess layer covering the fort at 10,20,30,50 and $80 \mathrm{~cm}$ depth and a second 2-m probe in front of the fort to evaluate spatial variations.

Time series show that most of the high-frequency contributions of water storage in the soil layer occur in the top $20 \mathrm{~cm}$. The soil then behaves as a non-linear filter and the deepest probes record essentially seasonal variations.

The calibration factor of gravimeters is determined with an uncertainty lower than $1 \%$ (e.g. Francis and Van Dam, 2002). As we do not want to use gravity data to calibrate the sensors, the soil moisture probes calibration has been undertaken on laboratory measurements, as follows:

- First, all the sensors are referenced with respect to a measure in air $\left(\theta=0 ; \varepsilon_{r}=3\right.$ in soils) and a measure in water $\left(\theta=1 ; \varepsilon_{r}=81\right)$. Sentek probes give a measurement of soil moisture $N$ between 0 and 1, which is not calibrated yet.

- Three soil cores per depth are extracted to determine their volumetric water content $\theta$ in laboratory. These cores of known volume are weighted before and after drying during 24 hours at $105^{\circ} \mathrm{C}$. No clear calibration function may be extracted from the relation between the Sentek measure $N$ and the laboratory determined soil moisture $\theta$. A third step is needed.

- An important step lies in converting the Sentek measure $N$ into relative permittivity $\varepsilon_{r}$ following Schwank et al., (2006). This nonlinear transformation determines the electronic behaviour of the probes and is independent to the soil.

240 - Finally, a second order polynomial is used to link the relative permittivity of the probes $\varepsilon_{r}$ to the water content $\theta$ determined in laboratory. The determined calibration curve is quite different from Topp et al. (1980) polynomial generally 
used to transform TDR measurements into soil moisture values. This is due to the particularities of loess soils

Figure 2 shows that this non-linear calibration is absolutely necessary in order to avoid an over-estimation of annual variations. For some sensors, the amplitude of the annual variation is divided by a factor 3. The error on the volumetric soil moisture estimation, determined on the calibration curves, has been reduced from $25 \%$ to $5 \%$ error thanks to this calibration process.

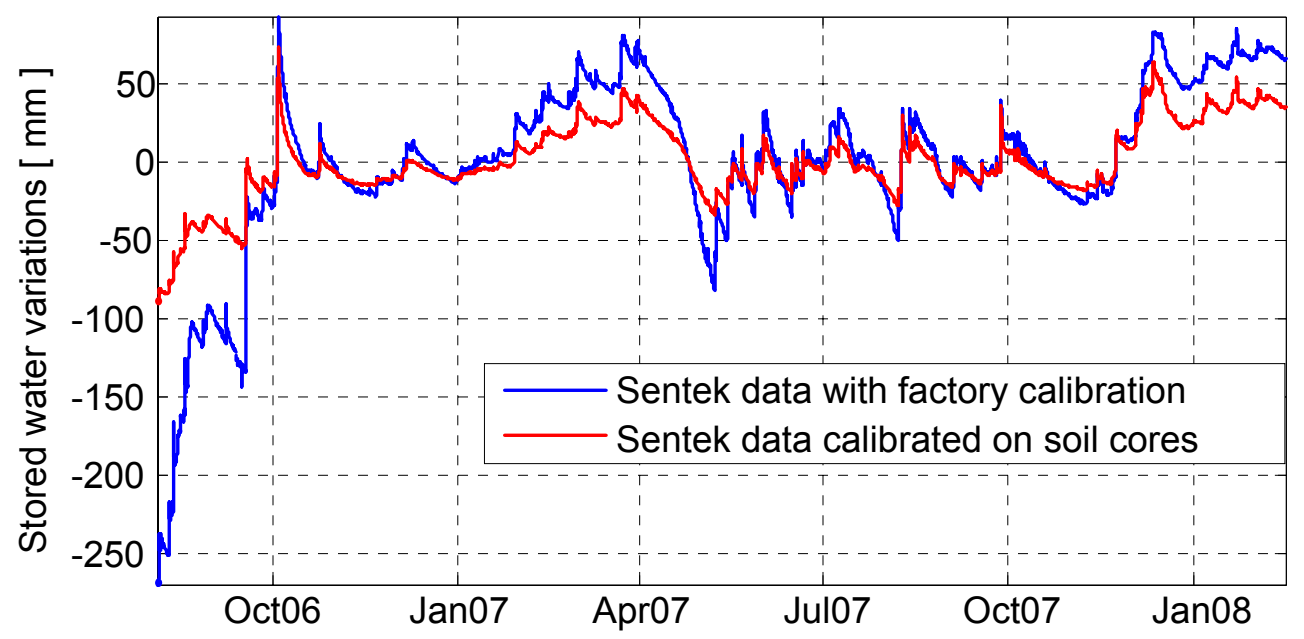

Figure 2: Stored water variations of the entire soil thickness above the gravimeter before 255 (blue) and after (red) calibration of the probes on soil cores. Note the highly nonlinear calibration.

\subsection{Distribution of water masses}

260 The calculation of Newtonian attraction needs to position the mass-test of the gravimeter inside its environment, i.e. to determine the relative position of the water masses.

A great attention was given to the geometry of the soil layer located above the gravimeter. Applied geophysics prospections have been carried out to evaluate the geometry of this layer. We have also performed a geomechanical investigation using a 
dynamical penetrometer called Panda (see http://www.sol-solution.com). The soil thickness is determined by knocking a series of metal rods. Moreover, the qualitative interpretation of the soil stiffness is used to evaluate the heterogeneities of the soil. The relative height between the gravimeter and the soil layer is finally determined using a 270 topographic survey, putting in obvious the 3-m concrete roof on top of the fort (see figure 3a). Note that this roof is a zeros flux limit condition for water that cannot be taken into account by global hydrological models.

A 25-cm vertical precision DTM has also been determined thanks to a RTK (Real-Time 275 Kinematic) survey. Note that the precision is estimated thanks to the nugget effect of the variogram. It has been connected to a regional DTM from the French Geographic Institute (IGN) to map a 2-km area around the gravimeter. The topographic map around the gravimeter is plotted on Figure $3 b$.

280 We calculate a realistic 'admittance' for the hydrological effect and the integration radius of the gravimeter by distributing uniformly a 1-mm water layer on the topography. Note that the integration radius and the calculated admittance are highly dependent on the topography around the gravimeter (Meurers et al., 2007). In J9 observatory, this integration radius is of the order of $100 \mathrm{~m}$ (see figure 3c). The final gravity effect of a 1$285 \mathrm{~mm}$ water layer is $-0.305 \mathrm{~nm} \cdot \mathrm{s}^{-2} \cdot \mathrm{mm}^{-1}$. This admittance only varies by $1.5 \%$ when the soil layer is shifted vertically by $1 \mathrm{~m}$. This is due to the fact that the distribution of the soil reservoir around the gravimeter is close to a half-plan. As a consequence, a single coefficient is used for the whole soil thickness. 


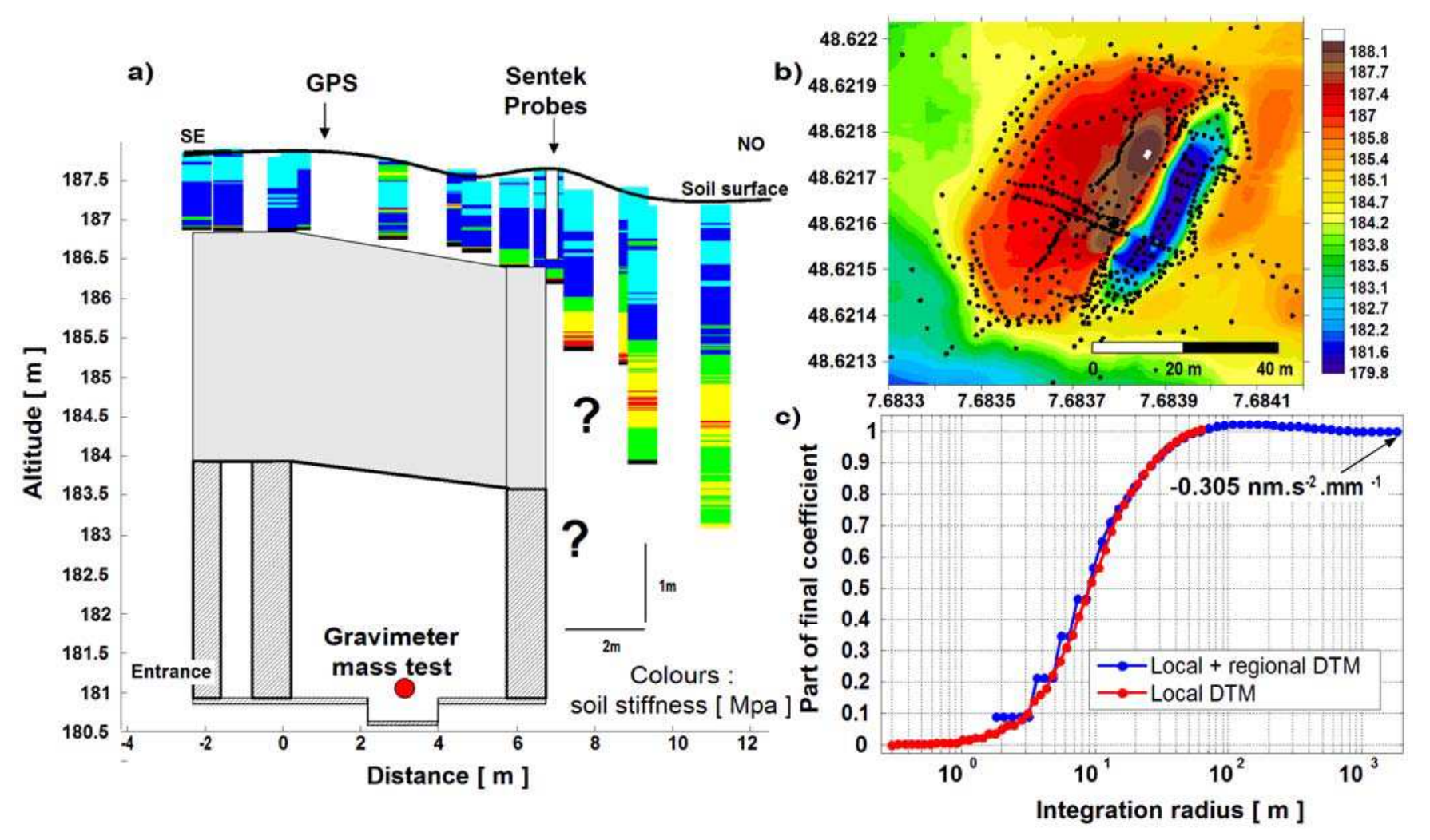

Figure 3: a) Fort and top soil layer geometry around the gravimeter mass test. The colours indicate the soil stiffness determined by the geomechical prospection. In grey, the geometry of the fort. b) Local DTM determined with RTK prospection around the gravimeter. c) Determination of the gravity effect generated by a 1-mm water layer uniformly distributed on the topography. The integration radius of the gravimeter is of the order of $100 \mathrm{~m}$, the final admittance is $-0.305 \mathrm{~nm} \cdot \mathrm{s}^{-2} \cdot \mathrm{mm}^{-1}$. 


\section{Results}

300

\subsection{Gravity and hydrological time series}

The processing of the superconducting gravimeter data is conducted as follows: Minute raw gravity and pressure data are first corrected from major perturbations (Crossley et al., 1993) and then filtered to hourly samples. Gravity are then corrected from polar motion and length-of-day induced effects (Wahr 1985), using EOPC04 series from the International Earth Rotation Service (IERS), assuming an elastic Earth and an equilibrium pole tide, including self-attraction and loading terms (Agnew \& Farrell 1978).

Atmospheric and induced non-tidal oceanic loading have been modelled using global surface pressure field provided by ECMWF (European Centre for Medium-range Weather Forecasts) and sea surface height variations from the HUGO-m (Carrère and Lyard, 2003) batropic ocean model, following Boy et al. (2002), Boy et Lyard (2008) and

315 Boy et al. (this issue). The loading time series will also contain some atmospheric residuals since the full 3-D atmospheric structure is not taken into account. This may lead to remaining effects at short term periods (especially linked to front movements) and a potential annual effect, below $10 \mathrm{~nm} . \mathrm{s}^{-2}$ for gravity (Neumeyer et al., 2004). Finally, tidal analyses are performed using the ETERNA package (Wenzel, 1997).

The 5-minute soil moisture measures are summed using weights representing the thickness integration of each sensor. These soil moisture variations, representative of the whole soil thickness are multiplied by the determined $-0.305 \mathrm{~nm} \cdot \mathrm{s}^{-2} \cdot \mathrm{mm}^{-1}$ coefficient. The results are finally decimated to hourly values.

The redistribution of water masses at continental scale is determined using GLDAS/Noah (Global Land Data Assimilation System) (Rodell et al., 2004), which is available on a $0.25^{\circ}$ grid with a $3 \mathrm{~h}$ temporal resolution. Green's function formalism (Farrell, 1972) is 
used to convolve water loads and calculate the associated gravity effect, assuming a SNREI earth.

Finally, a "deep hydrological contribution" is calculated. As stated previously, the local perched aquifer has been pointed out to induce gravity variations. One difficulty is that the water masses are creating a gravity signal below the gravimeter before reaching the 335 aquifer $35 \mathrm{~m}$ below ground. As a first order estimation, we have here multiplied the observed well variations by a $0.2 \mathrm{~nm} \cdot \mathrm{s}^{-2} \cdot \mathrm{mm}^{-1}$ coefficient calculated by Llubes et al. (2004) using a realistic geometry and porosity of the sand aquifer. This estimation is not exact but gives the shape of the long-term variations induced by deep water storage below the gravimeter.

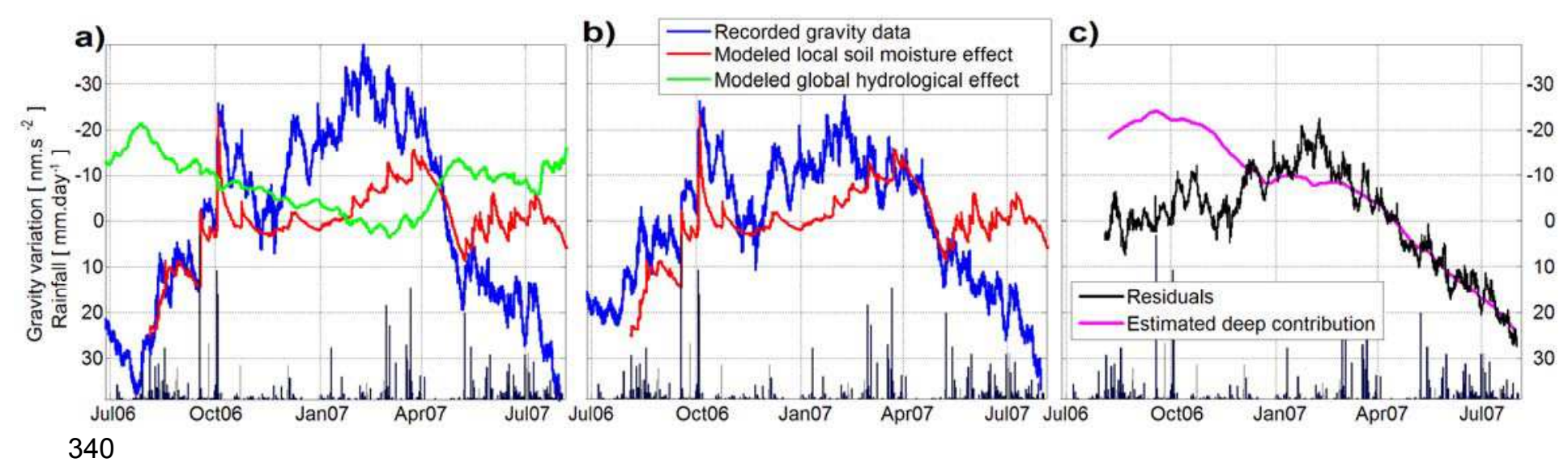

Figure 4: 1-year comparison between observed gravity signal and the modelled hydrological contributions. a) Gravity residuals (blue), modelled global contribution (green), modelled local contribution (red). b) Gravity residuals corrected from global hydrology (blue) superimposed with modelled local hydrology (red). c) Gravity residuals 345 after correction of global and local hydrological signals (black) and estimated deep contribution (magenta). Note that the vertical axis direction is drawn opposite to model rainfall inflows as a positive effect on gravity variations.

The comparison between the modelled hydrological contributions and gravity 350 observations is plotted on figure 4a. It should be noted that the global and local hydrological contributions are anti-correlated, as determined previously. The amplitude 
of the local hydrological signal is twice as important as the amplitude of the global hydrological effect.

355 On figure $4 b$, gravity residuals are corrected from global hydrology to better evaluate the quality of the local soil contribution. Every rainfall event is associated with a gravity effect; these are correctly described by our soil moisture probes. One interesting event happened in April 2007. This period was warm and dry is Strasbourg, which enabled a quick development of the vegetation and thus, the root pumping of a non negligible amount of water. The agreement for this 1-month event is very encouraging and allows us to validate our approach. Note that this period was warm and dry for the Europe as a whole. As a consequence, the global and local hydrological contributions are correlated, even at a monthly time scale.

365 The gravity time-series corrected from both global and local hydrological signals are plotted on figure 4c. Short period variations are especially due to unmodelled atmospheric effects. We confirm here that the water masses variations below the gravimeter only generate long-term variations. The estimated deep contribution partly explains the residuals; however, as stated previously, more work is needed to better constraint the vertical fluxes before water can reach the sand aquifer.

\section{Conclusion}

In this work, we have modelled the different hydrological contributions in J9 observatory 375 using a deterministic approach, i.e. without calibrating on gravity data. Both water redistribution at the scale of several hundred of meters around the gravimeter and water redistribution at continental scale induce a non negligible gravity effect of several microgals. Moreover, both are driven by climate and so are anti correlated and partly compensate each other at seasonal time scales in J9 observatory. This last remark is an aposteriori justification of the necessity to physically model the hydrological effect. Future improvement will focus on the estimation of stored water variations below the 
gravimeter. This deep contribution induces especially long-term variations and cannot be simply constrained using piezometric head time series alone.

\section{Acknowledgments}

This study has been carried out within the framework of the ANR/ECCO/PNRH Project "Hydrology and Geodesy". Jean-Paul Boy is currently visiting NASA Goddard Space Flight Center, with a Marie Curie International Outgoing Fellowship (N ${ }^{\circ}$ PIOF-GA2008-221753). Nicolas Florsch is currently welcomed at the Department of Mathematics and Applied Mathematics at Cape Town University, South Africa, and is granted by the French Organization "Institut de Recherche pour le Développement".

\section{Cited bibliography}

Agnew, D. C. and Farrell, W. E., 1978. Self-consistent equilibrium ocean tides, Geophys. J. R. astr. Soc., 55, 171-181.

Amalvict, M., Hinderer, J., Mäkinen, J., Rosat, S. and Rogister, Y. 2004. Long-term and 400 seasonal gravity changes at the Strasbourg station and their relation to crustal deformation and hydrology, J. Geodyn. 38, 343-353

Bittler, C. and Elsass, P., 2006. Banque régionale de l'aquifère rhénan - programme 2003-2006, rapport brgm/rp-5876-fr, Technical report.

Bower, D. \& Courtier, N., 1998. Precipitation effects on gravity measurements at the Canadian absolute gravity site, Phys. Earth. Planet. Int., 106(3-4), 353-369.

Boy, J.-P., J. Hinderer and P. Gegout, 1998. Global atmospheric loading and gravity, Phys. Earth Planet. Inter., 161-177.

Boy, J.-P., and Lyard, F., 2008. High-frequency non-tidal ocean loading effects on surface gravity measurements, Geophys. J. Int., 175, 35-45.

415 Carrère, C. and Lyard, F., 2003. Modeling the barotropic response of the global ocean to atmospheric wind and pressure forcing - Comparisons with observations, Geophys. Res. Lett., 30 (6), 1275, doi:10.1029/2002GL016473.

Crossley, D. J., Hinderer, J., Jensen, O. and Xu, H., 1993. A slewrate detection criterion applied to SG data processing, Bull. d' Inf. Mar'ees Terr., 117, 8675-8704.

Crossley, D., Hinderer, J., Boy, J.-P., \& De Linage, C., 2006. Status of the GGP satellite project, BIM, 142, 11423-11432. 
425 Dal Moro, G., and M. Zadro (1998), Subsurface deformations induced by rainfall atmospheric pressure: tilt/strain measurements in the NE Italy seismic area, Earth Planetary Science Letters, 164, 193-203.

Farrell, W., 1977. Deformation of the Earth by surface load, Review of Geophysics Space Physics, 10(3), 761-797.

Francis O. and van Dam, T., 2002. Evaluation of the precision of using absolute gravimeters to calibrate superconducting gravimeters, Metrologia 39 (2002), pp. 485-488.

Hasan, S., Troch, P., Boll, J., \& Kroner, C., 2005. Modeling the hydrological effect on local gravity at Moxa, Germany, Journal of Hydrometeorology, 7, 346-354.

Kroner, C., and T. Jahr (2006), Hydrological experiments around the superconducting gravimeter at moxa observatory, J. Geodynam., 41(1-3), 242-252, doi:10.1016/ j.jog.2005.08.012.

Llubes, M., Florsch, N., Hinderer, J., Longuevergne, L., \& Amalvict, M., 2004. Local hydrology, the global geodynamics project CHAMP/GRACE perspective : some case studies, Journal of Geodynamics, 38, 355-374.

Meurers, B., Van Camp, M., \& Petermans, T., 2007. Correcting superconducting gravity time-series using rainfall modelling at the Vienna and Membach station and application to earth tide analysis, J. Geodesy, 81 (11), 703-712.

Neumeyer, J., Hagedoorn, J., Leitloff, J. and Schmidt, T., 2004. Gravity reduction with three-dimensional atmospheric pressure data for precise ground gravity measurements, J. Geodynamics, 38 (3-5), 437-450.

455 Rodell, M., et al. (2004), The global land data assimilation system, Bull. Amer. Meteor. Soc., $59885,381394$.

Schwank, M., Green, T., Mätzlerc, C., Benedickterd, H., \& Flühlere, H., 2006. Laboratory characterization of a commercial capacitance sensor for estimating permittivity and inferring soil water content, Vadose Zone J., 5, 1048-1064.

Topp, G., Davis, J. L., \& Annan, A. P., 1980. Electromagnetic determination of soil water content : Measurements in coaxial transmission lines, Water Resour. Res., 16, 574582.

Virtanen, H., M. Tervo, and B.-K. M. (2006), Comparison of superconducting gravimeter observations with hydrological models of various spatial extents, in Bull. dInf. Mares Terr., 142, pp. 11,361-11,368. 
470 Wahr, J. M., 1985. Deformation induced by polar motion, J. Geophys. Res., 90 (B11), 9363-9368.

Wenzel H. G., 1997. The nanogal software: Earth tide data processing package ETERNA 3.30, Bull. d'Inf. Marées Terr., 124, 9425-9439.

475

Wilson, D., Western, A., \& Grayson, R., 2004. Identifying and quantifying sources of variability in temporal and spatial soil moisture observations, Water Ressources Research, 40, W02507.

480

17. 
Figure 1: monthly gravity residuals observed at several GGP stations after correction of tides, polar motion and atmospheric contribution. Stations are classified with respect to the relative position of the gravimeter with the local soil layer, above ground or below ground. Adapted from Crossley et al. (2006).

Figure 2: Stored water variations of the entire soil thickness above the gravimeter before (blue) and after (red) calibration of the probes on soil cores. Note the highly nonlinear calibration.

Figure 3: a) Fort and top soil layer geometry around the gravimeter mass test. The colours indicate the soil stiffness determined by the geomechical prospection. In grey, the geometry of the fort. b) Local DTM determined with RTK prospection around the gravimeter. c) Determination of the gravity effect generated by a 1-mm water layer 495 uniformly distributed on the topography. The integration radius of the gravimeter is of the order of $100 \mathrm{~m}$, the final admittance is $-0.305 \mathrm{~nm} \cdot \mathrm{s}^{-2} \cdot \mathrm{mm}^{-1}$.

Figure 4: 1-year comparison between observed gravity signal and the modelled hydrological contributions. a) Gravity residuals (blue), modelled global contribution (green), modelled local contribution (red). b) Gravity residuals corrected from global hydrology (blue) superimposed with modelled local hydrology (red). c) Gravity residuals after correction of global and local hydrological signals (black) and estimated deep contribution (magenta). Note that the vertical axis direction is drawn opposite to model rainfall inflows as a positive effect on gravity variations. 